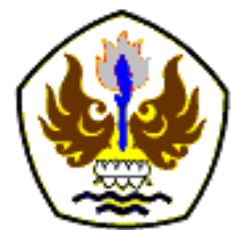

INFOMATEK

Volume 19 Nomor 1 Juni 2017

\title{
BUSINESS PLAN CV. CIHANJUANG INTI TEKNIK
}

\author{
Asep Saeful Bachri ${ }^{*}$, Cevy Septian Dinias \\ Program Studi Teknik Industri \\ Fakultas Teknik - Universitas Pasundan
}

\begin{abstract}
Abstrak: Seiring berkembangnya teknologi yang semakin modern memberikan pengaruh terhadap kegiatan ekonomi termasuk aktivitas bisnis pada suatu perusahaan, sehingga banyak terjadi persaingan yang kompetitif ditambah dengan adanya suatu perjanjian atau kerja sama di bidang Indsutri dan perdagangan yang dilakukan pemerintah Indonesia dengan negara lain yang disebut MEA. Dalam mengembangkan rencana bisnis atau business plan dimulai dengan analisis SWOT yang mencakup analisis Internal dan Eksternal perusahaan. Setelah analisis SWOT dibuat, maka selanjutnya menyusun rencana bisnis dimulai dari ringkasan eksekutif, uraian umum usaha, analisis aspek pemasaran sampai analisis aspek keuangan. Dari analisis SWOT didapatkan kekuatan, kelemahan, peluang, dan ancaman yang ada di perusahaan dan salah satu strategi dari hasil analisis SWOT yang menggunakan kekuatan dan peluang yang ada ialah Mempertahankan kualitas produk yang dimiliki oleh CV. Cihanjuang Inti Teknik yang ditujukan untuk para konsumen. Untuk hasil penyusunan rencana bisnis diketahui bahwa CV.Cihanjuang Inti Teknik bergerak pada industri makanan dan minuman tradisional khas Jawa Barat, memiliki potensi pasar yang baik, memiliki jenis produk yang beragam. Manajemen CV. Cihanjuang Inti Teknik sudah dapat dijalankan dengan baik dengan jumlah tenaga kerja yang ada sebanyak 53 orang. CV. Cihanjuang Inti Teknik memiliki nilai IRR sebesar 22,42\%, dengan nilai ROI sebesar 17\%. Dan nilai Profitability Index sebesar 1,37.
\end{abstract}

Kata kunci: Business plan, SWOT, industri makanan.

\section{PENDAHULUAN}

Seiring berkembangnya teknologi yang semakin modern memberikan pengaruh terhadap kegiatan ekonomi termasuk aktivitas bisnis pada suatu perusahaan. Isu yang saat ini hangat diperbincangkan oleh pemerintah Indonesia mengenai pasar global yaitu persiapan dalam menghadapi Masyarakat Ekonomi Asean atau yang biasa disebut dengan MEA. Masyarakat Ekonomi Asean (MEA) merupakan tujuan dari integrasi

\footnotetext{
*) asepsbrfei@gmail.com
}

ekomoni regional kawasan Asia Tenggara yang diberlakukan pada tahun 2015. Karakteristik MEA sendiri meliputi: (1) berbasis pada pasar tunggal dan produksi, (2) kawasan ekonomi yang sangat kompetitif, (3) wilayah pembangunan ekonomi yang adil, dan (4) kawasan yang begitu terintegrasi dalam hal ekonomi global (http://www.asean.org/, diakses 05 Februari 2016 [1]).

Dengan adanya penerapan MEA dapat memberikan peluang dan ancaman bagi 
industri dalam negeri. Seperti yang dikutip pada situs Kementrian Perindustrian menurut Erwin yang juga pengusaha dari Bosowa Group Erwin Aksa mengemukakan bahwa peluang untuk memasarkan produk dalam negeri ke pasar yang lebih luas di Negaranegara ASEAN akan terbuka dengan lebar. Hal itu antara lain didukung dengan aset yang sangat besar dan produk berdaya saing tinggi. Perusahaan-perusahaan tersebut khususnya bergerak di bidang makanan dan minuman, pertambangan, migas, dan perkebunan. Peluang tersebut sudah dimanfaatkan oleh sejumlah perusahaan dalam negeri seperti Indofood Sukses Makmur, Garuda Foods, Medco, Ciputra Development, Wijaya Karya, serta Grup Wilmar (http://www.kemenperin. go.id, diakses 01 April 2016 [2]).

Dalam memanfaatkan peluang yang potensial tersebut harus didukung dengan rencana bisnis atau business plan yang baik agar perusahaan dapat mengelola bisnis yang ada. Pengelolaan bisnis yang baik pun sangat diperlukan sebagai modal utama keberlangsungan hidup usaha terutama pengelolaan pada sektor-sektor yang penting pada usaha tersebut.

CV. Cihanjuang Inti Teknik (Cintek) bergerak pada dua bidang usaha yaitu rekayasa dan manufaktur pembangkit listrik tenaga air dan angin, dan bergerak di bidang makanan dan minuman tradisional Jawa Barat, Divisi makanan dan minuman tradisional mengelola industri agrobisnis dengan pemanfaatan bahan baku yang berasal dari pertanian dengan produk berupa minuman tradisional khas Jawa Barat yaitu bandrek dan bajigur. Merk dagang yang digunakan yaitu Hanjuang. Saat ini divisi makanan dan minuman tradisional telah memproduksi 12 jenis minuman yaitu bandrek, bajigur, kopi bandrek, enteh bandrek, bandrek spesial dewasa, coklat bandrek, kopi bajigur, beas cikur, sekoteng, bandrek panah arjuna, kopi panah arjuna dan satu produk baru yaitu green tea hanjuang. Selain itu, diproduksi juga 2 produk makanan yaitu keripik nangka dan stik pisang. Hal tersebut didukung dengan adanya data yang dapat dilihat pada Gambar 1 di bawah ini.

\begin{tabular}{|c|c|}
\hline \multicolumn{2}{|c|}{ Produk Potensial Ekspor Indonesia ke Asean } \\
\hline Produk Potensial Indonesia & Negara Tujuan Ekspor Ke Asean \\
\hline Kulit \& Produk Kulit & Vietnam, Malaysia, Thailand, dan Filipina \\
\hline $\begin{array}{l}\text { Peralatan dan instrumen } \\
\text { medis }\end{array}$ & Singapura, Malaysia, Thailand, dan Filipina \\
\hline Rempah-Rempah untuk obat & Malaysia, Singapura, Vietnam, dan Thailand \\
\hline Makanan Olahan & $\begin{array}{l}\text { Malaysia, Filipina, Singapura, Kamboja, Thailand, } \\
\text { Myanmar dan Vietnam }\end{array}$ \\
\hline Minyak Atsiri & Singapura \\
\hline Ikan \& Produk Ikan & Thailand, Vietnam, Singapura, dan Malaysia \\
\hline Produk Kerajinan & Singapura, dan Malaysia \\
\hline Perhiasan & Singapura, Thailand, dan Malaysia \\
\hline Spices & Vietnam, Singapura, Malaysia, dan Thailand \\
\hline Peralatan Tulis selain Kertas & Malaysia, Thaland, Filipina, dan Singapura \\
\hline
\end{tabular}

\section{Gambar 1}

Produk Potensial Ekspor Indonesia ke Asean (http://inforial.bisnis.com, diakses 05 Februari 2016 [3]) 


\section{METODE PENELITIAN}

Metode yang digunakan meliputi : Teknik Wawancara, Teknik Observasi Langsung, Studi Literatur, dilakukan pada pihak-pihak yang berwenang di perusahaan dan menggali data yang akan diperlukan, seperti data umum perusahaan, data internal perusahaan yaitu data yang berkaitan dengan lingkup perusahaan dan eksternal perusahaan yaitu data kondisi di luar perusahaan seperti aspek ekonomi, aspek politik dan pemerintahan, aspek sosial budaya, dan aspek teknologi.

\section{ANALISIS DAN PEMBAHASAN}

Setelah penyusunan strategi bisnis dilakukan, maka dilanjutkan pada penyusunan pengembangan business plan yang membahas rencana pemasaran, rencana produksi dan operasi, rencana manajemen dan organisasi serta membahas proyeksi keuangan perusahaan.

\subsection{Analisa Lingkungan Internal}

Dalam melakukan analisis lingkungan internal perusahaan, terdapat faktor-faktor internal perusahaan yang berkaitan dengan kekuatan dan kelemahan perusahaan yang dianggap penting yang dituangkan dalam matriks IFAS. Data dan informasi aspek internal perusahaan dapat digali lebih dalam yang berguna untuk menghadapi persaingan yang ada pada saat ini. Adapun hasil dari penyusunan matrik IFAS tersebut diantaranya: a) Kekuatan (Strength) :

1. Kualitas produk bandrek hanjuang yang baik.

2. Harga produk yang terjangkau oleh konsumen.

3. Hubungan baik dengan supplier.

4. Hubungan baik dengan distributor.

5. Memiliki jaringan distribusi hampir diseluruh wilayah Indonesia.

6. Merek produksi industri minuman tradisional bandrek hanjuang di mata masyarakat.

b) Kelemahan (Weakness) :

1. Kemampuan dalam melakukan pemasaran belum optimal.

2. Kemampuan dalam melakukan promosi belum maksimal.

3. Kapasitas produksi belum maksimal.

4. Pengaturan manajemen dan organisasi yang belum optimal.

Dari hasil matriks IFAS di atas terdapat nilai sebesar 3,120, dengan bobot tertinggi didapat oleh faktor kekuatan perusahaan yaitu kualitas produk hanjuang yang baik dengan bobot sebesar 0,120. Sedangkan untuk bobot nilai yang paling rendah didapatkan oleh faktor kelemahan perusahaan yaitu pengaturan manajemen dan organisasi yang belum optimal dengan bobot sebesar 0,094. 


\subsection{Analisa Lingkungan Eksternal}

Dalam melakukan analisis lingkungan internal perusahaan, terdapat faktor-faktor internal perusahaan yang berkaitan dengan peluang dan ancaman perusahaan yang dianggap penting yang dituangkan dalam matriks EFAS. Data dan informasi aspek internal perusahaan dapat digali lebih dalam yang berguna untuk menghadapi persaingan yang ada pada saat ini. Adapun hasil dari penyusunan matrik EFAS tersebut diantaranya :

a) Peluang (Opportunity):

1. Konsumen yang potensial.

2. Peningkatan pendapatan penduduk.

3. Peluang pasar yang luas dengan adanya MEA.

4. Kebijakan dan dukungan pemerintah terhadap produk minuman tradisional dalam negeri.

b) Ancaman (Threats)

1. Meningkatnya persaingan karena adanya MEA.

2. Perusahaan pendatang baru yang bergerak di bidang yang sama.

3. Selera konsumen yang selalu berkembang.

4. Terdapat pesaing yang memanfaatkan teknologi yang lebih canggih.

Dari hasil matriks EFAS di atas terdapat nilai sebesar 3,239, dengan bobot tertinggi didapat oleh faktor peluang perusahaan yaitu peluang pasar yang luas dengan adanya MEA dengan bobot sebesar 0,138. Sedangkan untuk bobot nilai yang paling rendah didapatkan oleh faktor ancaman perusahaan yaitu terdapat pesaing yang memanfaatkan teknologi yang lebih canggih dengan bobot sebesar 0,096. Dengan bobot paling tinggi yang didapatkan oleh faktor peluang perusahaan tersebut, maka perusahaan harus mampu memanfaatkan peluang pasar yang terbuka lebar agar dapat meningkatkan keuntungan bagi perusahaan.

\subsection{Analisis SWOT}

Berdasarkan hasil analisis terhadap kondisi lingkungan internal dan eksternal perusahaan CV. Cihanjuang Inti Teknik diperoleh faktorfaktor keukatan dan kelemahan perusahaan. Serta diperoleh juga peluang dan ancaman yang harus dihadapi perusahaan. Berikut ini merupakan hasil analisis SWOT :

\section{a) Strategi S-O (Strength- Opportunity)}

Strategi S-O adalah strategi yang menggunakan kekuatan internal perusahaan untuk memanfaatkan peluang-peluang yang ada di lingkungan eksternal perusahaan. Strategi S-O yang dihasilkan adalah market development strategy yaitu meningkatkan pangsa pasar dengan membidik pasar yang lebih luas karena adanya MEA.

b) Strategi S-T (Strength-Threats)

Strategi S-T adalah strategi yang menggunakan kekuatan internal perusahaan 
untuk menghindari atau mengantisipasi dampak dari ancaman yang berasal dari lingkungan eksternal perusahaan.

\section{c) Strategi W-O (Weakness-Opportunity)}

Strategi W-O adalah strategi yang dilakukan dengan meminimumkan kelemahan perusahaan untuk memanfaatkan peluang yang ada di luar perusahaan. Strategi W-O yang dihasilkan adalah brand image strategy yaitu menjadi sponsor local event yang berkaitan dengan peningkatan nama perusahaan di kalangan masyarakat serta melakukan promosi melalui media yang tepat dan juga meningkatkan kualitas SDM yang ada di perusahaan.

\section{d) Strategi W-T (Weakness-Threats)}

Strategi W-T adalah strategi untuk dapat bertahan dengan cara mengurangi kelemahan yang ada pada lingkungan internal perusahaan serta menghindari ancaman yang ada di luar perusahaan.

Strategi W-T yang dihasilkan adalah market penetration strategy yaitu meningkatkan pangsa pasar yang ada seperti MEA melalui perbaikan sistem pemasaran, melakukan pengembangan produk dengan melakukan inovasi, memanfaatkan teknologi yang semakin canggih.

\subsection{Penyusunan Pengembangan Business Plan}

Berdasarkan tahapan dari penyusunan pengembangan business plan dimulai dari ringkasan eksekutif dan uraian umum usaha, selanjutnya menganalisis pemasaran sampai dengan menganalisis keuangan perusahaan. Dari ringkasan eksekutif dan uraian umum usaha yang didapatkan dari perusahaan ialah CV. Cihanjuang Inti Teknik yang bergerak pada dua bidang bisnis yaitu divisi makanan dan minuman tradisional dan divisi teknik yang memproduksi mikrohidro atau turbin. Divisi makanan dan minuman tradisional mengelola agrobisnis dengan pemanfaatan bahan baku yang berasal dari hasil pertanian dengan produk yang dikenal masyarakat berupa minuman tradisional khas Jawa Barat yaitu bandrek dan bajigur.

\subsection{Analisa Pemasaran}

\section{a) Potensi Pasar}

Potensi pasar pada jenis makanan dan minuman tradisional yang bahan bakunya terbuat dari rempah-rempah asli Indonesia sangat tinggi karena kebutuhan pada setiap orang yang ingin merasakan minuman tradisional yang saat ini sudah jarang ditemukan atau sekedar hobi dan masyarakat.

\section{b) Marketing Mix}

Marketing mix atau bauran pemasaran yang dilakukan oleh perusahaan yaitu dengan 
menekankan bagaimana cara menjaga loyalitas para konsumen dan mencoba memperluas pasar melalui optimalisasi kegiatan produksi, serta pelayanan yang memuaskan konsumen dengan fasilitasfasilitas yang dimiliki.

c) Segmenting, Targeting, Positioning

\section{Segmenting}

Produk makanan dan minuman tradisional dipasarkan hampir di sleuruh wilayah Indonesia. Produk makanan dan minuman tradisional dipasarkan kepada hampir seluruh lapisan msyrakat Indonesia. Dengan adanya kerjasama antar Negara di Asean yaitu MEA.
Sebelum melakukan kegiatan penjulan, tentu sebuah perusahaan perlu untuk merumuskan "siapa yang akan membeli produk ini?". Melihat aspek kebutuhan konsumen akan makanan dan minuman tradisional, maka penjualan makanan dan minuman tradisional khas Jawa Barat ini di targetkan terhadap masyarakat di wilayah Indonesia yang sebagian besar menyukai olahan makanan dan minuman tradisional yang terbuat dari rempah-rempah asli Indonesia. Hal tersebut didukung dengan adanya data dibawah ini yang ditunjukan pada Gambar 2.

\section{Targeting}
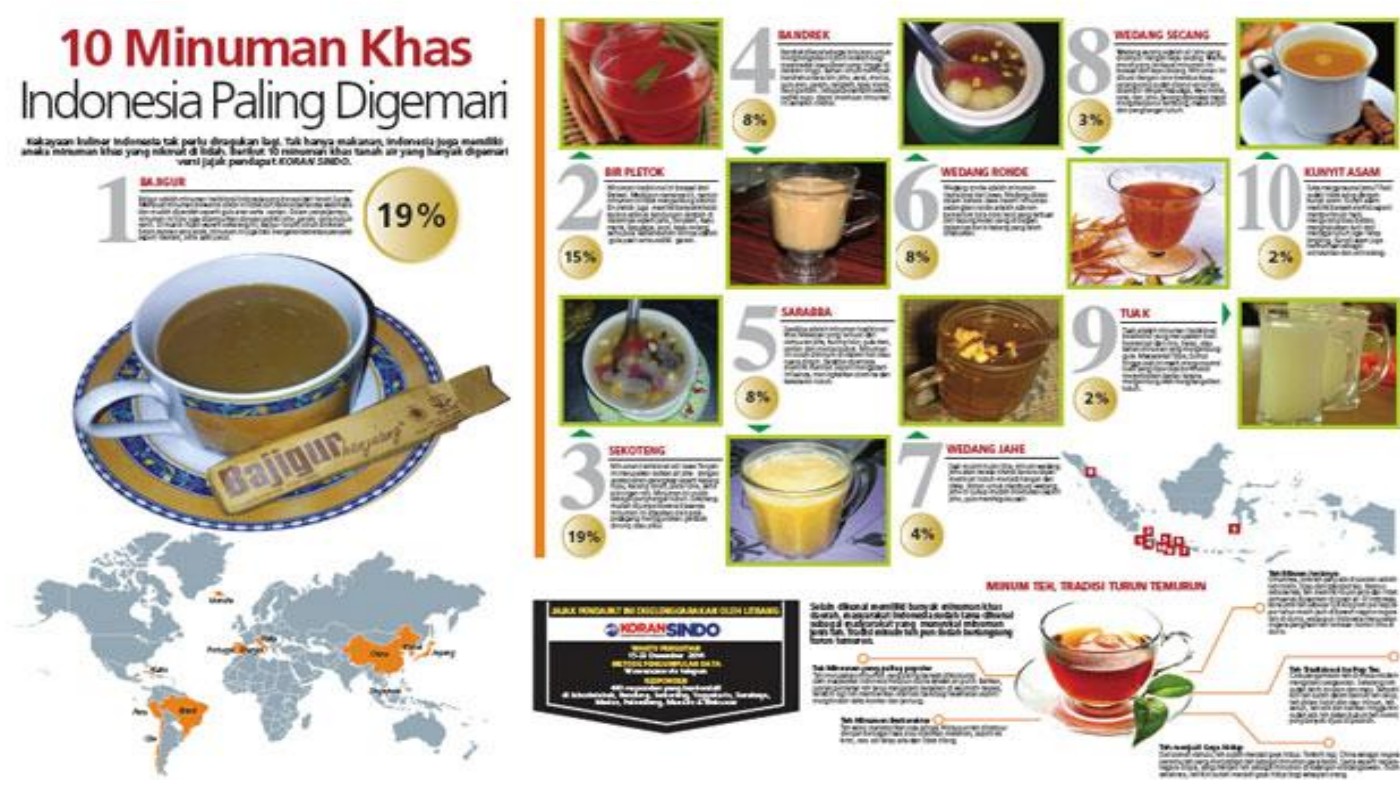

Gambar 2

Minuman Khas Indonesia Paling Digemari (http://nasional.sindonews.com, diakses 26 Februari 2016 [4]) 
3. Positioning

- Pangsa Pasar :

$>$ CV. Cihanjuang Inti Teknik : $28 \%$

$>$ Anget Sari Sidomuncul $\quad: 40 \%$

$>$ PT. PKM

$: 9 \%$

PT. Arum Sari Mas

Lain
$: 11 \%$

$: 12 \%$

- Tingkat Pertumbuhan pasar CV.

Cihanjuang Inti Teknik adalah

$\mathrm{TPP}_{\mathrm{N}}=\frac{\mathrm{VPI}_{\mathrm{N}}-\mathrm{VPI}_{\mathrm{N}-1}}{\mathrm{VPI}_{\mathrm{N}-1}} \times 100 \%$

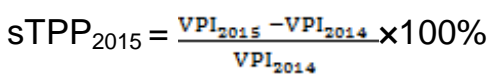

$\mathrm{TPP}_{2015}=\frac{633.652 .000-495.214 .000}{495.214 .000} \times 100 \%$

$\mathrm{TPP}_{2015}=27,95 \%$

- Pangsa pasar relative :

> PPR CV. Cihanjuang Inti Teknik

$=\frac{\text { Pangsa Pasar Cihanjuang }}{\text { Pangsa Pasar Anget sari }}$

$=\frac{28 \%}{40 \%}$

$=0,7$

$>$ PPR Anget Sari Sidomuncul

$=\frac{\text { Pangsa Pasar Anget Sari }}{\text { Pangsa Pasar Cíhanjuang }}$

$=\frac{40 \%}{28 \%}$

$=1,43$

PPR PT. PKM

$=\frac{\text { Pangsa Pasar PT.PKM }}{\text { Pangsa Pasar Anget Sari }}$

$=\frac{9 \%}{40 \%}$

$=0,23$

PPR PT. Arum Sari Mas

$=\frac{\text { Pangsa Pasar PT. Arum Sari }}{\text { Pangsa Pasar Anget Sari }}$

$=\frac{11 \%}{40 \%}$

$=0,28$

\subsection{Analisa Produksi dan Rencana Operasi}

a) Jenis dan Deskripsi Produk

1. Jenis Produk

Jenis produk dari CV. Cihanjuang Inti Teknik yaitu olahan makanan dan minuman tradisional khas Jawa Barat. Olahan makanan dan minuman tradisional ini terbagi dalam 10 jenis produk minuman yaitu bandrek original, bajigur original, kopi bandrek, enteh bandrek, coklat bandrek, kopi bajigur, beas cikur, sekoteng, bandrek ginseng special dewasa, dan satu produk baru yaitu green tea latte.

\section{Deskripsi Produk}

Produk minuman tradisional khas Jawa Barat ini sangat cocok untuk menghangatkan badan, selain itu baik juga untuk kesehatan. Semua minuman yang diproduksi terbuat dari bahan-bahan alami pilihan seperti gula palem atau gula jawa, gula putih, jahe, ginseng, pinang, kencur, beras, coklat, teh, sokade, kelapa, kismis, jeruk, purwaceng, tribulus 
terrestris, serta rempah-rempah dan tanpa pengawet buatan, dengan racikan komposisi yang tepat, diolah secara teliti dan higienis menghasilkan produk yang harum, gurih, nikmat, dan berempah.

b) Desain Produk

CV. Cihanjuang Inti Teknik telah memproduksi berbagai olahan minuman tradisional dengan bermacam-macam jenis produk dan desain kemasan dari produk tersebut memiliki perbedaan dan ciri khas tersendiri.

\section{c) Desain Proses}

Dalam proses pembuatan minuman tradisional khas Jawa Barat yang di produksi oleh CV. Cihanjuang Inti Teknik terdapat beberapa tahapan yang harus dilakukan. Tahapan tersebut dapat diuraikan sebagai berikut :

\section{Proses Sortir}

Proes ini merupakan proses awal dalam pembuatan minuman tradisional, karena proses ini akan menentukan bahan baku yang dipilih merupakan bahan baku yang berkualitas atau tidak.

\section{Proses Pencucian}

Proses ini merupakan lanjutan dari proses awal, dimana bahan baku yang telah disortir akan dicuci untuk membersihkan bahan baku dari kotoran agar bahan baku tetap higienis.

3. Proses Pematangan
Proses pematangan ini menggunakan mesin kukus.

4. Proses Pengirisan/Pemotongan Bertujuan agar bahan baku memiliki ukuran yang tidak terlalu besar sehingga memudahkan pada proses berikutnya.

5. Proses Pengeringan

Bertujuan untuk mengurangi kadar air yang ada, proses ini menggunakan mesin oven.

6. Proses Roasting/Sangrai

Proses ini merupakan proses sangrai, dalam proses ini akan membuat bahan baku menjadi semakin kering. Proses ini menggunakan mesin roasting.

7. Proses Penggilingan

Pada proses ini bahan baku akan digiling dengan menggunakan mesin grinder.

8. Proses Penimbangan

9. Proses Pencampuran/Mixing

Proses ini akan mencampurkan seluruh bahan baku yang digunakan dalam membuat minuman tradisional.

10. Proses Pengepakan

Proses yang terakhir yaitu proses pengepakan. Kemasan yang digunakan pada produk hanjuang ini memiliki dua jenis yaitu kemasan renteng dan kemasan selobong. 


\section{KESIMPULAN}

Menyusun rencana bisnis atau business plan yang tepat bagi CV. Cihanjuang Inti Teknik untuk dapat bertahan dan tumbuh berkembang di tengah persaingan yang begitu ketat dan dapat memenangkan persaingan bisnis terhadap competitor dengan beberapa langkah penyusunan rencana bisnis dimulai dari penyusunan strategi bisnis dengan menganalisis lingkungan internal dan lingkungan eksternal yang selanjutnya akan dianalisis dengan metode analisis SWOT. Selanjutnya menyusun pengembangan business plan dengan menganalisis aspek pemasaran dampai dengan aspek keuangan atau financial.

Membuat strategi fungsional dengan melihat pada aspek pemasaran, aspek keuangan, aspek operasional dalam menghadapi pesaing atau competitor yaitu sebagai berikut :

a) Strategi Pemasaran, Dalam aspek pemasaran terdapat beberapa kajian yang dibahas, yaitu :

- Potensi Pasar

- Marketing Mix

- Segmenting, Targeting, Positioning

- Pesaing/Competitor

b) Strategi Produksi dan Rencana Operasi

c) Aspek Organisasi dan Manajemen

d) Apek Keuangan atau Financial
Dari hasil analisis keuangan perusahaan diperoleh besarnya investasi yang diperlukan untuk mengembangkan rencana bisnis CV. Cihanjuang Inti Teknik yaitu sebesar Rp. 8.305.659.000. Dengan hasil analisis keuangan sebagai berikut :

- Laba Rugi yang menguntungkan, artinya laba bersih dari periode ke periode selanjutnya mengalami peningkatan yaitu pada periode awal sebesar Rp. 2.840.440.901 serta periode ke lima sebesar Rp. 5.228.434.414.

- Neraca yang seimbang dan menguntungkan, artinya total aktiva dan total pasiva memiliki nilai yang seimbang dan mengalami peningkatan yaitu sebesar $\mathrm{Rp}$. 16.736.517.759 pada periode pertama dan Rp. 20.759.725.028 pada period ke lima.

- Payback Period memperlihatkan bahwa perusahaan layak untuk mengembangkan bisnis yang ada karena modal dapat kembali dengan cepat pada periode ke empat atau pada tahun ke 4,44 atau pada bulan ke 52,4.

- Internal Rate of Return sebesar $22,466 \%$, artinya perusahaan layak untuk mengembangkan usaha pembuatan minuman tradisional 
Khas Jawa Barat untuk dapat bertahan dan dapat bersaing ditengah serbuan produk asing yang masuk ke dalam negeri karena adanya Masyarakat Ekonomi Asean atau MEA.

\section{DAFTAR PUSTAKA}

[1] http://www.asean.org/asean-economiccommunity/, diakses 05 Februari 2016
[2] http://www.kemenperin.go.id/artikel/ 3222/MEA-Peluang-Emas-bagiPengusaha-RI, diakses 01 April 2016

[3] http://inforial.bisnis.com/read/20151214/ 353/501739/mea-2015-peluang-barangdan-jasa-di-pasar-bebas-asean, diakses 05 Februari 2016; 9:40

[4] http://nasional.sindonews.com/read/ 963350/163/10-minuman-khasindonesia-paling-digemari-1423707474, diakses 26 Februari 2016; 12:28 